\title{
Tools for Teaching
}

\section{Presenting Relaxation Techniques to Pregnant Adolescents}

\author{
Mary Jo Podgurski, RNC, MA, LCCE, FACCE
}

MARY JO PODGURSKI is Director of The Washington Hospital Teen Outreach and the founder of the Academy for Adolescent Health, Inc. in Washington, Pennsylvania.

\begin{abstract}
Teens present a unique challenge for the childbirth educator. A committed educator must find creative teaching strategies that will ease an adolescent's tension and provide a safe environment where a teen can "own" the message of her body's ability to give birth. The author of this column presents one of her own strategies for teaching relaxation techniques to adolescents.

Journal of Perinatal Education, 9(3), 1-4; adolescence, pregnancy, teaching techniques, childbirth educators.
\end{abstract}

That is what learning is.

You suddenly understand something you've understood all your life, but in a new way.

—Doris Lessing

\section{Special Classes, Special Teens}

Working with underserved populations frequently provides a childbirth educator with opportunities for growth in her own life. Teens present a unique challenge, especially when their classes are taught while they are a "captive audience" in school. Adolescent pregnancy is a symptom of multifaceted problems in a young girl's life. Poverty, sexual abuse, and family dysfunction are just a few of the adult linkages to this teen problem (Luker, 1996). A committed educator may find herself presenting material to a group of less than enthusiastic participants. Although adults may also arrive in class with issues and baggage that color their perception of your message, teens present developmentally singular needs that compound their initial reluctance. At the same time, midwif- 


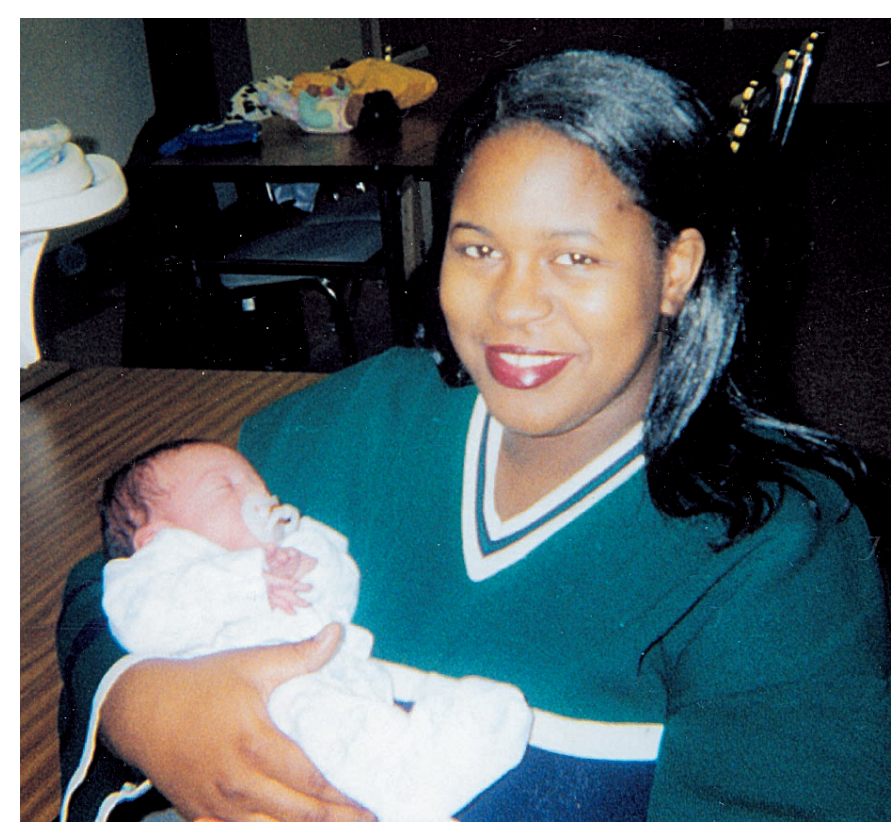

Teaching the basics of childbirth to pregnant teens-philosophy of birth, comfort measures, positioning, relaxation, and breathing-requires creativity and flexibility.

ing young mothers' discovery of their own inner wisdom is a task filled with joy and intangible rewards.

There is an art to reaching out to teens. Interactive techniques should overshadow any lecture that is presented. Not only do teens, like adults, retain more of what they do than what they simply hear, they often carry negative impressions of education that need to be overcome before they can "own" the message that their bodies know how to birth their babies.

A superintendent in one of our teen outreach schools articulated the following observation to one of my new childbirth educators nearly a decade ago: "Anyone can reach a kid who is willing to learn. You can only call yourself a teen educator when you get through to the kids who don't want to be there." His words of wisdom hold true today. There is one level of education when

"Anyone can reach a kid who is willing to learn. You can only call yourself a teen educator when you get through to the kids who don't want to be there." the participants are willing, enthusiastic, and open to your message and another level entirely when their presence is mandated. Teaching the basics-philosophy of birth, comfort measures, positioning, relaxation, and breathing-requires creativity and flexibility.

\section{Historical Perspective}

I remember the first time I literally stumbled upon the technique I've found most successful for presenting to teens the techniques of relaxation and focusing (see Table 1). It was a hot, muggy day in late spring. The room I normally used for my classes at the high school was occupied, the guidance office was swarming with young people, and the nurse's office had kids lined up down the hall.

I looked at the four teens in my class-two in their final trimester, one in her second trimester, and one newly pregnant-and remembered our last encounter the week before. The young woman with the first due date had just transferred to our district and had joined the group only two sessions ago. Her addition had transformed the delicate group dynamics I'd worked so hard to develop. The reality of her situation was stark. Only she and I knew that her pregnancy was a result of incest. Her attitude towards her baby, the other girls in the

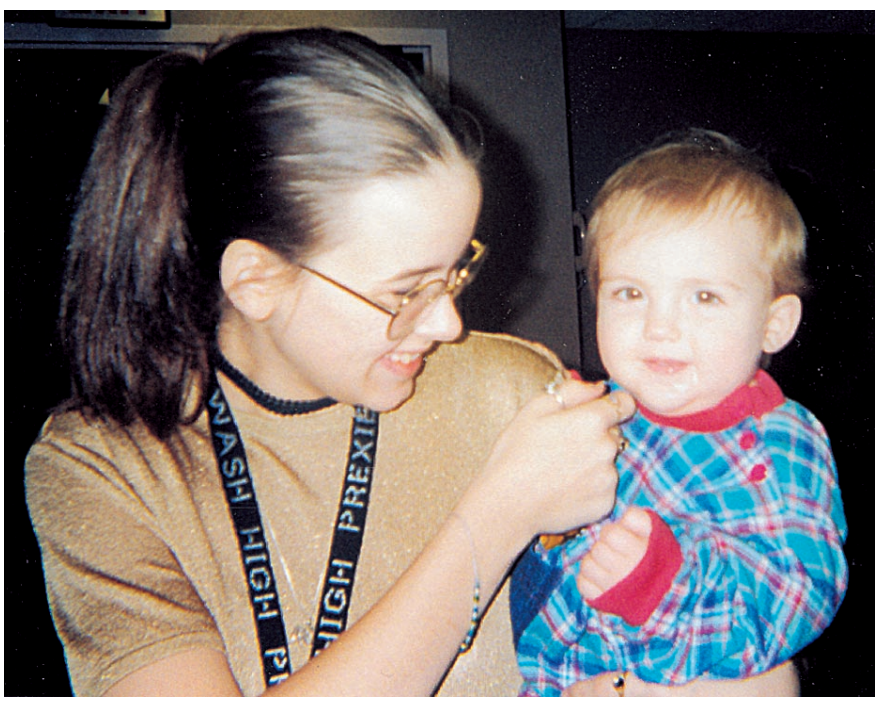

Midwifing young mothers' discovery of their own inner wisdom is a task filled with joy and intangible rewards. 
Table 1 The "How Tos" of the "Lean on Me/Being There" Relaxation Teaching Technique for Adolsecents

\begin{tabular}{|c|c|c|c|}
\hline Behavioral Objectives & Teaching Technique & Hints on Instructing Teens & Rationale/Evaluation \\
\hline $\begin{array}{l}\text { At the conclusion of the } \\
\text { session, the participants } \\
\text { will be able to: } \\
\text { 1. Discuss the role of } \\
\text { relaxation, } \\
\text { positioning, and } \\
\text { focusing in preparing } \\
\text { for labor and birth } \\
\text { 2. Demonstrate basic } \\
\text { breathing } \\
\text { 3. Discuss the }\end{array}$ & $\begin{array}{l}\text { "Lean on Me/Being There" } \\
\text { Relaxation } \\
\text { - Participants should select a } \\
\text { partner, forming a dyad for the } \\
\text { experience. If a partner already } \\
\text { accompanies the teen, that } \\
\text { person is the obvious choice. A } \\
\text { single teen is often most } \\
\text { comfortable choosing someone } \\
\text { from the class. } \\
\text { - Each couple should give }\end{array}$ & $\begin{array}{l}\text { The educator should discuss } \\
\text { basic principles of relaxation } \\
\text { and focusing as comfort } \\
\text { measures, drawing upon daily } \\
\text { living to reinforce the normalcy } \\
\text { of this response. Examples of } \\
\text { stress situations in adolescent } \\
\text { life in which relaxation } \\
\text { techniques may be helpful: } \\
\text { taking a driving test, taking } \\
\text { SATs, preparing to go out with }\end{array}$ & $\begin{array}{l}\text { - Teens are often ill at ease } \\
\text { performing relaxation. They } \\
\text { can most easily release tension } \\
\text { if not observed. This position } \\
\text { provides support and physical } \\
\text { contact while minimizing eye } \\
\text { contact and face-to-face } \\
\text { experiences. Teens can quietly } \\
\text { tune into their partner's } \\
\text { breathing pattern and style } \\
\text { without feeling threatened. }\end{array}$ \\
\hline
\end{tabular}

experience of feeling a partner's breathing pattern

4. Share individual needs and perceptions about labor, birth, and childbearing

- Each couple should give permission for simple touch. The educators may reassure the teens about the nonsexual nature of this touch.

- Each dyad sits on the floor, back-to-back, providing support for one another.

- Ask one person to identify him or herself as Partner A and the other as Partner B.

- Sit quietly, listening to soft music if the participants choose to do so.

- Ask Partner A to simply pay attention to each breath Partner B takes. After a short interval, switch roles. No counting is necessary, but the partners should focus closely on the rhythm and depth of each other's breathing.

- Take a few minutes to allow the partners to process and discuss the experience.

- Resume the back-to-back position, this time allowing the dyad to initiate breathing when ready. Notice the way each partner leans on the other, shifting weight until both are comfortable.

- Process and discuss the experience.

- You may ask each person to take note of other aspects of his or her partner's body-movement, restlessness, signs of uneasiness.

- Process and discuss. someone new, and -in the case of a pregnant or parenting teen-telling someone in your family about the pregnancy.

- Do not discuss practice or demonstration at this time. It is imperative that the teens feel they are in control of the exercise.

- Observe how carefully each person takes notice of his or her partner's breathing. Centering on someone else's patterns provides a strong focus. Teens have shared with me that the stress of the day disappears as they become empathic to their partner's experience. At the same time, since they have no eye contact, neither person is "on display."

- Once again, control should belong to the teens.

- Couples often progress from this simple exercise to more complicated positions that involve eye contact and touching. This exercise serves as an icebreaker.

- I have repeatedly found that the participants tailor their own breathing to match their partners'.

- You may easily add simple imagery-for example, the suggestion of a color each person chooses that becomes lighter with each breath. As a general rule, do not provide any sort of guided visualization.
This exercise is a perfect segue into a discussion of support-what is needed, what is lacking, and what is wanted-in the teen's life as she prepares for labor, birth, and childbearing.

- Images that are pleasing to one person may be threatening to another. With the frequency of sexual abuse and emotional trauma in this population, avoiding guided imagery is a much safer exercise. You may direct each person to find his or her own "safe place."

- Asking couples to share what color was chosen by each partner often results in interesting, perceptive discussions. class, and the philosophy of birth I tried to weave throughout my sessions was overwhelmingly negative. When we seemed to have no place to practice the comfort measures I'd introduced earlier to the class, she rolled her eyes and suggested she return to study hall. "This stuff is all BS anyway," she snorted. I looked at the other 
... [during] the final 5 minutes [I learned] what I already knew-relaxation comes from within. It is not the teacher who gets you there, but yourself.

girls. Willing, but not exactly eager, they seemed to be teetering on the brink of agreeing with her.

The hallway where we deliberated was so intensely hot and the out-of-doors so attractive that I spontaneously suggested we have class outside. A few moments later I found myself with a new problem: There were no chairs, no backrests, and no soft areas that would easily support relaxation. Without thinking, I suggested that the four teens lean back against each other and use each other's bodies as back support. I sat cross-legged in front of them and tried to decide what I could possibly present to them when they were facing two different directions.

They appeared comfortable, at least, and the air was much cooler. Compared to the hustle and bustle of the school, this setting was almost idyllic. We all sat quietly as I deliberated what to do. My tape recorder was battery-operated and I popped in a gentle instrumental cassette. The girls' silence was peaceful. Only the soft music and outside sounds- the birds, the wind, and the sound of our breathing-broke the quiet.

I suddenly remembered a relaxation exercise I'd participated in as a young childbirth educator. I'd attended a national conference, eager to learn new teaching techniques. A well-respected educator had scheduled a predawn relaxation session. I'd roused myself from bed to attend it at 6:00 a.m., hoping to absorb some of her experience and wisdom. When I arrived, the presenter was seated in the front of the room with her cassette player. She welcomed us all, began the music, and was totally silent. There were no other directions, no guided imagery, and no verbal instruction of any sort. For 15 minutes, we sat in silence. I spent the first 5 minutes confused; the second 5 minutes annoyed that I'd missed sleep; and, finally, the final 5 minutes learning what I already knew-relaxation comes from within. It is not the teacher who gets you there, but yourself.

On that hot May day with my own class members, I began to realize what I needed to do to reach this eclectic group of teens. I simply asked, "What do you feel?" One of the girls immediately said, "I can feel her breathing." I knew exactly where to go from there. Necessity helped me discover a teaching technique I've found to be successful with even the most reluctant participant. It eases

It eases initial feelings of discomfort associated with normal adolescent embarrassment while tapping into inner wisdom in a way no words can articulate.

initial feelings of discomfort associated with normal adolescent embarrassment while tapping into inner wisdom in a way no words can articulate.

Two weeks later, as I served as doula for my most resistant class participant, I referred to that session and saw her body ease away from tension in response. "Let go, let it happen" were only words to her before she truly "leaned" on a friend and began to open up.

\section{Reference}

Luker, K. (1996). Dubious conceptions: The politics of teenage pregnancy. Cambridge, MA: Harvard University Press.

\section{Thoughts on Teaching}

Find a subject you care about and which you feel others should care about. It is this genuine caring, and not your games with language, which will be the most compelling and seductive element in your style.

-Kurt Vonnegut, Jr.

Example is always more efficacious than precept.

—Samuel Johnson 